\title{
Las formas sígnicas de la cultura cañari. Un enfoque del diseño en bolsas ecológicas
}

\section{The symbolic forms of the Cañari culture. An approach to green bag design \\ Recibido: 15/06/2020 \\ Aceptado: 15/07/2020}

\author{
Douglas Armando Quintero Bastardo ${ }^{1}$, Catalina Pauta ${ }^{2}$, Marco Pazmiño 3 \\ 1. Coordinador de Seguimiento a Egresados y Graduados del Instituto Superior Tecnológico Particular Sudamericano, Cuenca, Ecuador. \\ Email: daquintero@sudamericano.edu.ec ORCID: https://orcid.org/0000-0002-1437-2732 \\ 2. Docente Titular Instituto Tecnológico Superior Particular Sudamericano. \\ Email: c.pauta@sudamericano.edu.ec ORCID: https://orcid.org/0000-0001-6381-7294
}

3. Docente Titular Instituto Tecnológico Superior Particular Sudamericano. Email: mpazmino@sudamericano.edu.ec ORCID: https://orcid.org/0000-0002-2852-1065

Para Citar: Quintero Bastardo, D. A., Pauta, C., \& Pazmiño, M. (2020). Las formas sígnicas de la cultura cañari. Un enfoque del diseño en bolsas ecológicas. Revista Publicando, 7(25), 202-211. Recuperado a partir de https://revistapublicando.org/revista/index.php/crv/article/view/20g6

\begin{abstract}
Resumen: La provincia de Azuay cuenta con un patrimonio cultural reconocido nacional e internacionalmente por su estética arquitectónica y su riqueza arqueológica. Parte de esa herencia fue desarrollada por los pueblos ancestrales asentados en Tomebamba, hoy ciudad de Cuenca. En cuanto a los orígenes de la cultura Cerro Narrío, también conocida como Chaullabamba, la revisión bibliográfica confirma que surge al sur de los andes ecuatorianos; donde se encuentran ubicadas en la actualidad las provincias del Cañar y el Azuay, considerada antecesora de los cañaris. El presente proyecto se fundamenta en el análisis morfológico de las memorias sígnicas culturales (formas y figuras) del pueblo Cañari, lo que aportará a la preservación de la identidad cultural y al mantenimiento del patrimonio intangible de las culturas aborígenes de la provincia del Azuay desde la perspectiva del diseño ecologista, sustentable y sostenible. Para ello, se desarrolló una investigación de campo, a través de una encuesta diseñada para tal propósito, a una población desde los 18 hasta los 65 años de edad que nos permitió recabar los criterios necesarios para el diseño de las formas sígnicas de la simbología Cañari, acompañados de frases y eslogan, que enfatizan una serie de temáticas dirigidas a la preservación del legado cultural y educativo, siendo los principales aportes del proyecto, apoyados en principios básicos del diseño gráfico como: los trazos, formas, cromáticas, tipografías, texturas y mensajes utilizados para la divulgación de todos estos aspectos representativos de las cultura Cañari.
\end{abstract}

Palabras clave: Formas sígnicas, cultura, diseño, cañari.

\begin{abstract}
The province of Azuay has a cultural heritage that is recognized nationally and internationally for its architectural, archaeological, intangible, and documentary wealth. Part of that cultural plenitude was developed by ancient cultures settled in the Tomebamba plains, today Cuenca. Regarding the origins of the Cerro Narrio culture, also known as Chaullabamba, the bibliographic review confirms that it arises in the southern part of the Ecuadorian Andes, current provinces of Cañar and Azuay; it was considered ancestor of the Cañaris. This project is based on the use of cultural memories for the preservation of identity, contributing to the maintenance of intangible heritage through forms and figures of aboriginal people of the Province of Azuay, from the perspective of ecological, sustainable, and sustainable design. The goal of the research revolves around the promotion of values, attitudes, levels of awareness of indigenous roots, and preservation of the cultural identity of the habitat. The data and information were collected through fieldwork, interviews with key subjects, involvement in designs, representation of symbology in visual media, with phrases, slogan, and figures emphasized in a series of themes aimed at preserving the cultural and educational heritage. The main contributions of the project are based on fundamental principles of graphic design such as: pieces, shapes, colors, fonts, textures, and messages used for the dissemination of all these representative aspects of the Cañari culture.
\end{abstract}

Keywords: Sign shapes, culture, design, Cañari. 


\section{INTRODUCCIÓN}

$\mathrm{E}$ 1 enfoque del diseño en bolsas ecológicas como principal temática de investigación se sustenta en lo establecido por el Instituto Nacional de Patrimonio Cultural (INPC), creado bajo decreto ejecutivo 816, publicado en el registro Oficial No. 1246 de 7 de enero de 2008, el cual dictó políticas de preservación de patrimonio y, en la actualidad se encuentra levantando el inventario de bienes patrimoniales. Con la finalidad de profundizar en la preservación de los valores culturales y bienes ancestrales como patrimonio de la humanidad, la intervención de la tecnología, el mundo de la globalización y la permanente alienación de los medios de comunicación arropado por la sociedad del consumismo poco a poco han penetrado las culturas ancestrales, tal como lo reflejan algunos indicadores que se presentan en el documento Indicadores UNESCO de cultura para el desarrollo, manual metodológico (UNESCO, 2016). En dicho documento se plantea la necesidad de abordar desde el sistema educativo y en los espacios no formales comunitarios la educación para la identidad y significación de la cultura en el caso de estudio, la cultura Cañari.

Desde el análisis morfológico de los símbolos culturales, se promoverá que la población en general se aproxime a su identidad y arraigo cultural, desde la participación, el reconocimiento de los signos, las imágenes y significados de cada elemento cultural. El fundamento del presente proyecto se centra en la recopilación de figuras, formas, cromáticas e información relevante de las culturas aborígenes del Azuay, perteneciente a la Zona 6 del Ecuador, para divulgar todos estos aspectos representativos de la cultura nacional. El propósito del proyecto es la generación de una serie de gráficas mediante el uso de las herramientas digitales del diseño, con una mirada contemporánea a la simbología de la cultura en cuestión, para ello se pretende realizar un estudio que integre aspectos que determinen un target, cromática, semiología, abstracción de las formas mediante un análisis morfológico de las formas sígnicas de la cultura Cañari.

La gráfica obtenida pretende aplicarse a productos que deberán permitir la impresión gráfica de cualquier tecnología existente en el mercado nacional, que garantice su calidad por un tiempo determinado, considerando sus costos también como factor de ahorro.
Las bolsas ecológicas que servirán de soporte gráfico además llevarán textos de apoyo motivacionales tanto culturales como ecológicos, que son la fuente de inspiración de este proyecto. La investigación pretende impulsar el uso de alternativas ecológicas para el reemplazo de los productos contaminantes del mismo modo se busca dar a conocer detalles representativos para la preservación de las culturas ancestrales con una contemporánea a sus símbolos característicos.

\section{DESARROLLO}

En lengua Kichwa "cañari" (o kañari), proviene de "kan" que significa culebra y "ara" que significa guacamaya. De acuerdo con expertos en la lengua, cañari significa descendientes de la culebra y de la guacamaya (Suárez, 1878). Desde esta perspectiva, la serpiente se interpreta como la madre tierra y la guacamaya como la deidad solar.

Reinoso (2017), en su libro "Cañaris e Incas, Historia y Cultura" habla sobre otra hipótesis del origen de la palabra cañari. Relata que existía una planta que daba frisoles de diversos colores llamados cáñaros; planta que según las investigaciones fue muy útil en el desarrollo y consolidación del pueblo Cañari, y que supuso el origen de Cañaribamaba y de sus pobladores los Cañaris.

La revisión documental indica que la culebra y la guacamaya, como elementos generadores de vida, de la tierra, del agua o una especie de deidades, dieron origen a esta tribu que data del periodo de desarrollo regional, alrededor de los 500 años antes de Cristo y cuyo principal asentamiento, de acuerdo con investigaciones realizadas fue en lo que actualmente son las provincias de Azuay y Cañar del territorio ecuatoriano. Sin embargo, según algunas evidencias encontradas tendrían también su asentamiento en las provincias de Morona Santiago, El Oro, Loja y Chimborazo.

El pueblo Cañari conocido tradicionalmente por ser tierra de guerreros y labradores de la tierra se asentó en zonas territoriales privilegiadas por su clima, abundante agua, páramos y pajonales, que les permitió alimentarse y protegerse del clima propio del territorio. 
Físicamente, las mujeres Cañaris, según algunos cronistas como Pedro Cieza de León describía en su Crónica del Perú, el Señorío de los Incas (2005) eran de presencia física muy hermosa, con cabellos largos, profundos ojos. Leales, abnegadas y obedientes a sus esposos; se dedicaban a cuidar a sus hijos, atender a sus esposos, participar de las labores de la tierra, como la siembra, deshierba y cosecha de los frutos, en definitiva, contribuían positivamente a la economía familiar.

Los varones, de características físicas semejantes a los nativos y aborígenes americanos, mongoloides, de contextura robusta, color de piel trigueño con algunas particularidades propias de la región, guerreros, respetados y temidos en la región.

Con estas características y descripciones físicas, ¿cómo los Cañaris pudieron ser tan influyentes y temidos a la vez en la historia del Tahuantinsuyo, y posteriormente cómo influenciaron en la naciente república del Ecuador? Varias respuestas se pueden citar.

Una primera respuesta evidentemente viene dada, sin duda por su organización política y de gobierno que fue de fundamental importancia. Se organizaron en señoríos, comandados por Caciques bajo normas de autonomía e identidad cultural que devenía de su influencia territorial y geográfica. Estos señoríos dieron lugar a la confederación Cañari, que compendian según las investigaciones realizadas por Alfredo Lozano Castro en su libro Cuenca, ciudad prehispana: significado y forma (1991), de 96 pueblos, 24 señoríos y 7 comunidades menores. Entre los pueblos representativos estaban los Hatun Cañares, Azogues, Cañaribambas, Racares, Cumbes, entre otros.

Fray Gaspar de Gallegos, párroco de lo que hoy es San Francisco de Peleusí de Azogues, capital de la provincia de Cañar, en 1582 escribía un relato sobre la organización política del pueblo Cañari,

Solían ser gobernados cada parcialidad de su cacique principal, y este cacique principal, que se llamaba Puezar, traía siempre guerra con la provincia de Hatun Cañar que está a 4 leguas de aquí; y algunas veces iban los caciques a pelear unos con otros; y tenían sus términos señalados de cada pueblo; y cuando iban los de aquí a dar batalla a los de Hatun Cañar, salían ellos al encuentro a los términos de sus pueblos; y así traían sus guerras antes que el Inga viniese; y que peleaban con unas mazas que tenían hechos de madera... (Reinoso, 2017, p. 107).

Breve descripción de los principales símbolos de la cultura Cañari

La serpiente: animal sagrado para la cultura Cañari, de hecho, animal mitológico, proveniente de las raíces propias del pueblo y de la leyenda que edificó la creencia de su nacimiento. Aparece en muchas representaciones a lo largo de toda su historia y la cultura Cañari. Está presente en una de las leyendas del origen del pueblo Cañari, visible en cerámicas en las distintas fases de formación del pueblo Cañari, como Cashaloma, Tacaishapa, Narrío y su utilización en festividades tradicionales (Cabrera, 2016).

La guacamaya: según la leyenda, la guacamaya tenía cabello largo atado o entrelazado. Se cree que de ellas nacieron tres varones y tres mujeres que dieron origen al pueblo Cañari, luego de una gran inundación en la zona (Suárez, 1878). Este ser mitológico está presente en varios aspectos de la cultura Cañari, está presente en diferentes rituales cañarís, sobre todo de tinte religioso, con conocidos colores y formas vistosas y considerada mensajera de la divinidad, de la deidad, del poder.

La luna: deidad mitológica, quizás según las interpretaciones de los estudiosos la más importante para la cultura Cañari. Representa la evolución continua, cambio permanente, transformación, representado en múltiples altares destinados a la adoración de las deidades, a través de imponentes rituales sagrados, Guamán (2016). Según la mitología la luna puede invadir los territorios de la deidad del sol y aparecer durante el día. Representada en el calendario que permitía generar un registro del tiempo, sobre todo para las siembras y las cosechas de los productos que cultivaban. Curiosamente, de acuerdo con diferentes investigadores, no existe mucha representación de la Luna en cerámicas y otros objetos de uso del pueblo Cañari. No obstante, su representación simbólica se efectuaba en imponentes rituales religiosos.

Las montañas: los cerros y montañas para el pueblo Cañari eran elementos fundamentales para sus rituales religiosos. Según la mitología, allí se asentaban las pacarinas, cuyo significado es "lugar de origen" y que inició los linajes andinos. Se citan como símbolos emblemáticos cerros como el Fazayñán, Guagualzhumi, Cojitambo, el cerro de Pucará y Barashigua en la cordillera occidental, también el cerro 
Supayurco, cerca de la actual parroquia Cumbe, el cerro Guagualzhumi, ubicado en la Parroquia rural Paccha del cantón Cuenca, capital de la provincia del Azuay, según estudios efectuados representa el nacimiento del sol y la luna, encajado en la vieja ciudad Cañari Guapondelig, que fue el santuario religioso más importante de la época (Torres, 2010).

Las lagunas: como parte de las últimas investigaciones realizadas Arizala Martínez y Merchán Andrade (2010), coinciden con los estudios más antiguos en cuanto a que en el territorio donde se asentó el pueblo Cañari, se localizaron varias lagunas de enorme importancia divina para su cultura, ubicadas en los cuatro puntos cardinales: al Norte, Culebrillas. Al Sur, Leoquina o Busa, hoy cantón San Fernando, al Occidente, las lagunas de los páramos del Cajas, y al Oriente, cerca del cantón Sígsig, la laguna de Ayllón, donde según la mitología se sumergió de sus entrañas y aguas heladas, el fundador de toda la nación Cañari.

\section{Cosmovisión de la cultura Cañari}

Ahora bien, en este punto de la investigación se hace necesario reflexionar sobre la cosmovisión de la cultura Cañari.

En este sentido es importante destacar que, antes de la conquista incaica, la nación Cañari era uno de los pueblos más importantes de lo que es hoy el territorio ecuatoriano. Poseían una rica cosmovisión andina, a través de la cual explicaban e interpretaban la realidad de su cultura con base en su medio natural; expresado y representado en diferentes mitos, prácticas y creencias que se han conservado a lo largo de la historia.

Los Cañaris conceptualizaban al mundo como un todo animado, todo lo que le rodeaba, lo que crecía, tenía vida y que esta vida estaba cargada de alma. Partían para su explicación del mundo de los cuatro elementos de la naturaleza, que según la creencia tenían vida animada: agua, aire, tierra y fuego.

La Pachamama: se refiere a la madre tierra o madre naturaleza, símbolo maternal, de fertilidad donde se desarrolla el ciclo de vida. Su representación aún vigente hoy en día en la vestimenta, en los bordados, en los vestidos y blusas. El Cañari se consideraba hijo de la tierra, amaba su tierra, la trabajaba con mingas, con esfuerzo colectivo, la protegía, la miraba con respeto, la vivía en comunidad (Pichisaca, 2001).

Jaway: mitología que permitió a los Cañaris ensalzar las bondades de la madre tierra en agradecimiento a los frutos que esta les daba, a través de las cosechas de productos como el maíz, trigo, cebada. El Inti Raymi; festival que coincidía con el solsticio de verano, fue en la antigüedad y se mantiene hoy como una de las manifestaciones en las cuales la celebración, el conjunto de danzas, rituales solemnes, música y cantos se entremezclan para rendir honor a la tierra y a las bondades de la naturaleza (Pichisaca, 2001).

La divinidad de los tres mundos. De acuerdo con Quinapallo (2019), en su cosmovisión, el pueblo Cañari comprendió que el universo estaba formado por tres mundos, tres partes o tres realidades que se interrelacionaban entre sí, que desprendían energías; les proporcionaba vida y prosperidad: el Hahua Pacha o Hanan Pacha, considerado como el mundo de arriba o mundo superior, el del firmamento, espacio donde habitaban las divinidades, las deidades; el Kay Pacha, el mundo de aquí, de ahora, espacio donde habitan los hombres, las plantas, los animales junto a los espíritus cobijados por la Pachamama; el Uku Pacha, el mundo inferior, mundo de abajo, lugar donde residen los espíritus, el mundo de los muertos, de los antepasados.

La divinidad de la dualidad. Los Cañarís entendían al mundo como un todo equilibrado, compuesto por un opuesto, o su par, un complemento, así se representó lo masculino y femenino, dando género a todo, a las montañas, las plantas, los astros, las divinidades entre otros.

Girardello et al. (1993), sostienen que el dualismo se corresponde con el conjunto de doctrinas sobre las cuales, en el ámbito del plano cósmico, “admiten la existencia de dos principios en oposición polar y conflictual, por lo tanto, inconciliables, con frecuencia en el centro de una mitología, y que se interpretan de forma personal" (p. 53). Esta concepción de dualidad se extendió desde los Cañaris hasta toda la comunidad andina, y según algunos investigadores concluyeron, que los procesos de la naturaleza y sus mundos eran entendidos a través de la complementación de la ideología sexual, de género, de opuestos.

La Chakana o cruz del sur. Es una forma sígnica emblemática de la cultura andina utilizada por los pueblos indígenas 
asentados en la Cordillera de los Andes como la cultura inca (sur de Colombia, Ecuador, Perú, Bolivia, Chile y Argentina) y también algunas culturas pre incásicas de Perú y Bolivia. Según algunas investigaciones posiblemente en Ancash, Huánuco y el Norte de Lima precolombino se haya nombrado como tsakana; símbolo utilizado por los cañaris como parte de su cultura, su visión de la realidad y del mundo que habitaban (Timmer, 2003).

En cuanto a su estructura, la cruz del sur consta de cuatro escalones de tres peldaños: dos superiores y externos y dos inferiores e internos colocados de manera precisa y simétrica mientras que en la parte central tiene inscrita un círculo dividido en dos partes iguales. De acuerdo con Belsuzarri (2017), los peldaños externos superiores corresponden a la representación del "Mundo ideal", la escalera derecha comprende la Teoría Cosmogónica mientras que la izquierda explica la Teoría de los tres mundos (Hanaq Pacha, Kay Pacha, Ukhu Pacha). Los escalones inferiores e internos refieren a lo que denominaron el Mundo Real; mientras la escala de la izquierda representa las diversas normas de conducta y sobre todo los principios básicos de la relación humana. Por otro lado, la escala derecha identifica el orden jerárquico inalterable en la sociedad cañari: política, social y religiosa.

\section{LA INVESTIGACIÓN}

Hasta aquí se ha hecho una revisión de la principal bibliografía que sustenta el significado de la simbología dejada por la cultura Cañari como legado a las futuras generaciones. Seguidamente, se presenta la sustentación de la investigación, sobre la base de una encuesta realizada en función de la proyección de la población de la provincia realizada por el INEC. Se tomó una muestra de 384 habitantes, con el 95\% de confianza y un margen de error del $\pm 5 \%$ distribuidos a nivel urbano y rural, considerando que el $67 \%$ de la población está asentada en zonas urbanas y el 33\% en zonas rurales de la provincia. Geográficamente se consideró los cantones de Cuenca, Gualaceo y Paute que en conjunto representan el $81,15 \%$ del total de la población de Azuay, con el objetivo de medir el conocimiento que tienen sobre la significación de las formas sígnicas de las culturas ancestrales del Ecuador, en particular de la cultura Cañarís y Cerro Narrío.
La primera variable considerada para la investigación tuvo que ver con la edad del encuestado, donde el 46,02\% correspondieron a edades comprendidas entre los 18 y 34 años, el $42,98 \%$ entre los 35 a 54 años y el 11\% representan a ciudadanos que superaban los 55 años.

Una segunda interrogante consistía en determinar si el encuestado tenía conocimiento sobre alguna cultura precolombina, entre las alternativas de respuesta se nombran las culturas: Cañarís, Cashaloma, Cerro Narrío, Tacalshapa. Al respecto, la mayoría de los encuestados exactamente un $67.1 \%$ tiene conocimiento de la cultura Cañari, el 11,31\% ha escuchado sobre la cultura Cashaloma, el 6,37\% sabe de la existencia de la cultura Cerro Narrío, mientras que el 10,79\% no conoce sobre las culturas precolombina de la zona austral.

En cuanto a los medios a través de los cuales la población obtuvo información sobre las culturas ancestrales existentes en el continente americano y en particular en el territorio del Ecuador, se evidenció que los medios impresos con un $31,27 \%$ y televisivos con $30,38 \%$ son las principales formas de información, mientras que la radio con $20,38 \%$ y las redes sociales con un $17,97 \%$ son también fuentes importantes donde la población tuvo conocimiento sobre las culturas precolombinas. Esta variable denota la importancia de la difusión a través de programas culturales en periódicos y televisión.

En otra interrogante se presentan una serie de gráficos correspondientes a la cultura Cañari (Figura 1), solicitando que el entrevistado seleccione el que mayor atención le produce desde el punto de vista de su diseño o simbología.
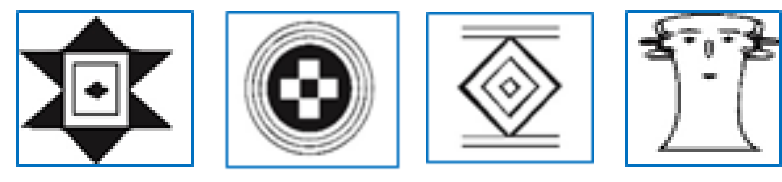

Figura 1. Signos cañaris (Reinoso, 2017).

Un 37,65\% de los encuestados manifiesta que la cruz inscrita en circunferencia es la que más les atrae, seguido de las jarras con figuras faciales con un 31,64\%, mientras que la figura con diversos rombos fue elegida por el 19,29\%, finalmente la figura conformada por los triángulos fue seleccionada por el $11,42 \%$. 
Sobre la disposición de utilizar elementos que contengan estos diseños impresos con tecnología textil en materiales no desechables, por ejemplo, en bolsa para hacer compras, usar para envolver, guardar accesorios u otros objetos personales, etc., la mayoría de la muestra estudiada representada por el 95,62\% está de acuerdo con el uso de una bolsa reutilizable como forma de contribuir con la conservación del medio ambiente $y$, que a su vez promueva la divulgación de la cultura Precolombina. Además, el 94,64\% considera importante que se deben insertar mensajes alusivos al respeto, que la cultura Cañari guardaba a la madre naturaleza.

Sobre qué eventos o actividades se deben realizar en la sociedad ecuatoriana con el objetivo de promover la utilización de bolsas reutilizables y la difusión del legado cultural; más del 80\% de los encuestados considera las visitas a las escuelas, colegios, universidades; instituciones públicas y privadas, parques, estadios, entre otros. Un dato interesante que reflejó la investigación fue que el 29,77\% de los consultados cree necesaria la difusión a través de mecanismos virtuales utilizando cualquiera de las plataformas disponibles en las redes sociales.

También se consultó acerca de la concientización que se debe generar sobre la contaminación que causan las bolsas de material plástico no biodegradables al ambiente, al respecto, El $97 \%$ de los encuestados está de acuerdo que se deben implementar medidas para la reducción de su uso. Es importante decir que, las bolsas plásticas no biodegradables se han eliminado en casi todos los países de Latinoamérica dando paso a bolsa reutilizable y bolsas biodegradables, por lo cual la población tiene de cierta forma conciencia de su beneficio para la naturaleza.

La fase final de la encuesta tuvo como propósito analizar los principales espacios en los cuales se debe promocionar la implementación de las bolsas ecológicas con diseños de las formas sígnicas de la cultura Cañarí. En tal sentido, se indagó sobre los principales centros o recintos comerciales de la ciudad en los cuales realiza sus compras. Alrededor del 40\% de los encuestados realiza sus compras en supermercados, un $37 \%$ en mercados populares, mientras que un $23 \%$ realiza sus compras en tiendas de barrio, evidencia, por lo tanto, que estos establecimientos deben ser considerados como espacios potenciales para la implementación de la propuesta. De igual manera, se pueden desarrollar eventos en los centros comerciales donde se ubican estos supermercados.
Una vez analizada la opinión de los pobladores de la provincia del Azuay sobre la necesaria difusión de la simbología de la cultura Cañari, se procedió al planteamiento desde el diseño gráfico de metodología para el diseño de las formas significas de la cultura Cañari en bolsas ecológicas.

\section{Metodología para el diseño de las formas sígnicas de la} cultura Cañari en bolsas ecológicas

Al hablar de diseño, hacemos referencia a un proceso que implica ciertamente una serie de pasos para el logro de un producto creativo desde la perspectiva visual. En palabras de Wong:

a diferencia de la pintura y la escultura, que son la realización de las visiones personales y los sueños de un artista, el diseño cubre exigencias prácticas. Una unidad de diseño gráfico debe ser colocada frente a los ojos del público y transportar un mensaje prefijado. Un producto industrial debe cubrir las necesidades de un consumidor (2013, p. 41).

La historia del diseño como disciplina data de las primeras décadas del siglo XX. A principios de 1922 en Gran Bretaña, el publicista William Addison por primera vez usó la frase “Diseño Gráfico".

Según Bob Cotton (1994), el diseño gráfico es fundamental en el problema de procesar y comunicar el enorme y creciente flujo de información de una economía global, una economía que depende del acceso rápido y preciso a los derechos procedentes de todas partes del mundo es por ello, que es un vínculo cada vez más importante en el proceso que reúne al transmisor de la información con su receptor.

En articulación con la investigación, se precisa que la cultura Cañari es muy rica en la expresión de formas, debido a la infinidad de elementos en cuanto a su diseño se refiere; inspirados en la naturaleza realizaban abstracciones con una marcada importancia tomando como énfasis elementos que a la vez se convirtieron en sus deidades, entre éstas se encuentran: la luna, el sol, la serpiente, la guacamaya, las montañas, la chacana; formas geométricas como cuadrados, espirales entre otros.

De tal manera que, la aplicación de técnicas propias del diseño gráfico para la incorporación de las formas sígnicas de la cultura Cañarí en bolsas ecológicas constituye un proceso en el cual se deben poner en práctica elementos de diversas 
disciplinas como la semiótica, la semiología, el análisis iconográfico, así como la utilización de técnicas de diseño como son la radiación, repetición, traslación, gradación y contraste; $y$, por supuesto, el manejo de imagen basado en la teoría del color. En tal sentido, se detallan los elementos teóricos sobre los que se fundamenta el diseño de las formas sígnicas de la cultura Cañari.

\section{SEMIÓTICA}

A través de la semiótica que es la ciencia de los signos, se procedió a realizar el análisis del mensaje icónico de los signos de la cultura Cañarí a nivel connotativo, buscando encontrar los elementos constitutivos, los mensajes de significación y de comunicación, las relaciones internas, que nace de la interacción entre los diferentes elementos internos del signo, para así poder comprender las relaciones semánticas entre el interpretante, el espectador y el lector.

\section{SEMIOLOGÍA}

Definida como la ciencia que estudia todo lo que involucra la vida de los signos en el contexto social (Saussure, 1983). Los principios y postulados de esta ciencia son de gran importancia para la investigación para el abordaje de los signos Cañaris y el análisis del funcionamiento de estos, su agrupación o no agrupación en diferentes sistemas, y el origen o formación.

\section{ICONOGRAFÍA}

El Icono de acuerdo a Charles Peirce, "representa al objeto en tanto que se parece a él, esto es, expresa a su objeto como similar a él por virtud de algún carácter suyo propio, independientemente de que el objeto al que representa exista realmente o no" (Barrena, 2014). La iconografía Cañari básicamente resulta como consecuencia de una creencia, una divinidad o una cosmovisión, dentro de las más importantes se destacan:

- Iconografía zoomorfa: con énfasis en animales muy importantes dentro de su cultura, la realización de este tipo de elementos era de uso diario, en algunos casos los utilizaban en eventos ceremoniales o religiosos.
- Iconografía antropomorfa: con formas humanas, éstas eran en base a representaciones de sus dioses o sus gobernantes, este tipo de objetos varía según el uso y se hallan realizados en materiales como metal (oro y plata, entre otros), cerámica y en algunos casos piedra.

- Iconografía abstracta: estas formas son las más usadas y fueron destinadas a la decoración en general, se repiten en varios de los vestigios encontrados junto con la simetría y la repetición de figuras, haciendo que las mismas ofrezcan un gran punto de partida para la obtención de diseños siendo inspiración para varias propuestas.

- Iconografía fitomorfa: la naturaleza también fue parte de su expresión, aquí la representación se asemejaba a la flora del lugar.

Los elementos más importantes dentro de la iconografía Cañari tomados en cuenta para esta investigación y que se han mencionado anteriormente, se resumen en: la Serpiente, la Guacamaya, el Chakana, la Luna y el Sol.

De igual manera, la cultura Cañari usa la simetría en la composición de sus gráficos decorativos, tanto en cerámica como textiles, está presente en la Fase Narrío, Tacalshapa y Cashaloma. Dentro de la operatoria del diseño es una de las razones principales por la que fue tomada en cuenta para la realización de este proyecto.

En el caso de los signos a implementar en las bolsas ecológicas con técnicas del diseño gráfico, la simetría permite el logro de un perfecto equilibrio visual, así como la posibilidad de colocar los elementos que conforman la composición gráfica de todo diseño a una misma altura, de diferentes lados, posee la misma selección cromática, las mismas texturas, y en general, permite semejar un espejo cuando se coloca cualquier objeto frente a él.

Fundamentos del diseño gráfico utilizadas para la creación de las formas sígnicas en bolsas ecológicas 
Principalmente, la retícula como herramienta que facilita una mejor evolución en el diseño y a través de su estructura permitirá lograr mayor equilibrio en las composiciones, ordenando de una mejor manera los textos e imágenes referidos a la cultura abordada.

Así mismo, la radiación que consiste en un giro de formas unitarias alrededor de un centro común con el objetivo de lograr un efecto radiante en las formas sígnicas desarrolladas. $\mathrm{Al}$ referirnos a la radiación como otra técnica del diseño gráfico, resaltamos el cambio de posición de una figura sin producir un cambio en su dirección inicial. Contrariamente a esta técnica, la repetición define el uso constante de la misma forma; puede estar restringida a la figura o a cualquier elemento específico con variaciones en otros elementos como figura, tamaño, color o textura. Ambas técnicas hacen posible la definición de las figuras de manera compleja.

La traslación de una forma hace cambiar su posición. Sin embargo, la dirección de la forma permanece invariable. La traslación es la repetición de una forma en un diseño. En las composiciones formales, las formas sometidas a traslación están espaciadas regularmente, pueden ser verticales, horizontales, diagonales o una combinación de ellas.

Por otra parte, la gradación representa el cambio gradual en una serie de formas unitarias en una secuencia ordenada (Wong, 1991). Mientras que el contraste representa la combinación de diferentes intensidades o niveles de oposición, en el color, tamaño y la textura, las cuales pueden proporcionar mayor significado a una composición (Sanchez, 2013). Por su parte para Dondis (2017) el mejor contraste se logra combinando tonos de dos colores que se encuentren lo más alejado posible de la gama del circulo cromático.

Así mismo, la teoría del color agrupa lo físico y lo perceptual, permitiendo relacionar el color a una sensación. El color es un aspecto fundamental en el diseño, es considerado una sensación subjetiva y puede trasmitir o dar la sensación de limpio, frío, cálido, alegría, las mismas que pueden variar en cada persona, esto debido a las interpretaciones y preferencias personales $\mathrm{o}$ factores culturales. Los colores primarios en la síntesis sustractiva, mezclados en diferentes porcentajes se obtienen los demás colores $\mathrm{y}$, de estos se derivan los colores secundarios que se obtienen de la mezcla en iguales porcentajes de los colores primarios. Colores terciarios, estos surgen de la combinación en una misma proporción de un color primario y otro secundario adyacente.

En cuanto a la tipografía, se la relaciona con las letras, con las palabras, con el texto; y éste es el punto de partida que permite considerar la tipografía como el concepto clave de la comunicación visual (Martin, 2009). Al igual que sucede con los colores o las imágenes, las tipografías también transmiten emociones y sensaciones, por tanto, una influencia en el mensaje que se desea transmitir. Las fuentes tipográficas se agrupan en: Serif, Sans Serif, Script y Decorativas.

Las técnicas del diseño gráfico utilizadas para el proceso de estampado de las formas sígnicas en bolsas ecológicas serigrafías y sublimación.

\section{CONCLUSIONES}

El análisis de las formas sígnicas correspondientes a la cultura Cañari ha sido posible a través de la participación de la comunidad, quienes aportaron para la recopilación de formas y figuras, así como información relevante de esta cultura aborigen.

A través de la impresión de los diseños de las bolsas ecológicas se aporta hacia la conservación de la cultura y su conocimiento a las nuevas generaciones. Constituyendo de esta manera un aporte significativo a la sociedad a través de la consolidación de saberes en el análisis y fundamentos del diseño.

Los fundamentos del diseño gráfico y las técnicas actuales aplicadas a la creación de las formas sígnicas en las bolsas ecológicas permiten una mirada contemporánea de los signos dando una nueva imagen a los elementos culturales.

Es importante resaltar que está publicación forma parte del proyecto de investigación titulado: las formas sígnicas de la cultura cañari. un enfoque del diseño en bolsas ecológicas, desarrollado a través del financiamiento del Instituto Tecnológico Superior Sudamericano como contribución para la conservación de la Cultura Cañari. Las técnicas del diseño aplicadas para la modernización de las formas sígnicas se convierten en un aporte metodológico para la formación de tecnólogos de alta calidad en el Ecuador. 


\section{REFERENCIAS BIBLIOGRÁFICAS}

Arizala Martínez, M. Á., \& Merchán Andrade, J. C. (2010). Proyecto de investigación y producción de un documental fotográfico sobre la arquitectura, áreas poblacionales, sitios arqueológicos y rutas de acceso de la Cultura Cañari (Tesis de Licenciatura).

\section{Google Scholar}

Barrena, Nubiola (2014) Charles S. Peirce: Creatividad y significación. Hacia una estética pragmatista, Universidad Pontificia Bolivariana, Medellín.

Google Scholar

Belsuzarri, H. (2017) Religión y masonería, los Dioses voladores. Tomo 1. Tres puntos editores, Lima.

Cabrera Viteri, K. M. (2016). Revista comunicacional fotográfica Cosmovisión del pueblo Cañari (Tesis de Licenciatura).

Google Scholar

Caillet-Bois, J. (1953). Un olvidado cronista: fray Reginaldo de Lizárraga (ca. 1539-1609). Nueva Revista de Filología Hispánica, 7(3/4), 600-607.

Google Scholar

Cotton, B. (1994). La nueva guía del diseño gráfico. Blume, Barcelona.

Google Scholar

De Cieza de León, (2005), Crónica del Perú, El Señorío de los Incas, Fundación Biblioteca Ayacucho.

Google Scholar

De Lizarraga, R., de Ortiguera, T., del Rio Marañon, J., \& Sánchez-Barba, M. H. (1968). Descripción breve de toda la tierra del Perú, Tucumán, Río de la Plata y Chile. Atlas.

Google Scholar
Dondis, D. (2017). La sintaxis de la imagen. Introducción al alfabeto visual. Editorial Gustavo Gili.

Google Scholar

Girardello, G., Filoramo, G., \& Barbero, V. (Eds.). (1993). Dizionario delle religioni. Einaudi.

Google Scholar

Guamán Yugsi, W. R. (2016). CAÑAR: Cultura y tradición (Tesis de Licenciatura).

Google Scholar

Lozano Castro A, (1991). Cuenca, ciudad prehispana: significado y forma. Abya Yala, Quito.

Google Scholar

Martín, J. Manual de tipografía del plano a la era digital. Campgrafic, séptima edición.

Google Scholar

Pichisaca, I. Q. (2001). Historia del Pueblo Cañari. Revista Yachaikuna, 1.

Google Scholar

Quinapallo Martínez, C. A. (2019). La cosmovisión andina del pueblo Otavalo en la actualidad a través de la narrativa popular (Tesis de Licenciatura, Quito: UCE).

\section{Google Scholar}

Reinoso Hermida, G. (2017). Cañaris e Incas. Historia y cultura. Tomo I. Cuenca, Editorial Don Bosco.

Sánchez, M (2013). Los principios fundamentales del diseño. Insigne, revista virtual de diseño gráfico. México.

Google Scholar 
Suárez, F. G. (1878). Estudio histórico sobre los Cañaris, antiguos habitantes de la provincia del Azuay. Quito: Biblioteca nacional del Ecuador Eugenio Espejo.

Google Scholar

Saussure, F (2008). Curso de lingüística general. Lozada, Buenos Aires.

Google Scholar

Timmer, H. (2003). La Chakana. ONG La Chakana. Obtenido de Alquimia.

Torres, E. (2010). Título: Diseño de una historia ilustrada, basada en la Mitología Cañari "Origen de los Cañaris” (Tesis doctoral, Universidad de Cuenca).

Unesco (2016). Indicadores UNESCO de cultura para el desarrollo, manual metodológico. Paris.

Wong, W. (2011). Fundamentos del diseño. Editorial Gustavo Gill. 